\title{
MATERNAL SMOKING DURING PREGNANCY, BEHAVIORAL PROBLEMS AND SCHOOL PERFORMANCES OF THEIR SCHOOL-AGED CHILDREN
}

\author{
Lubomír Kukla ${ }^{1}$, Drahoslava Hrubá2, Mojmír Tyrlík ${ }^{3}$ \\ ${ }^{1}$ Research Institute of Preventive and Social Paediatrics, Faculty of Medicine, Masaryk University, Brno, Czech Republic \\ ${ }^{2}$ Department of Preventive Medicine, Faculty of Medicine, Masaryk University, Brno, Czech Republic \\ ${ }^{3}$ Department of Psychology, Faculty of Philosophy, Masaryk University, Brno, Czech Republic
}

\begin{abstract}
SUMMARY
Background: Child behavior and school performance is influenced by many genetic and environmental factors including prenatal exposure to chemical neurotoxins contained in cigarette smoke. The European Longitudinal Study of Pregnancy and Childhood (ELSPAC) prospective study which in the Czech Republic incorporates a cohort of children born in the years 1991/2 in Brno city and the Znojmo district also allows to analyze the relationships between prenatal cigarette smoke exposure and the occurrence of behavior and learning disorders.

Methods: Using questionnaires repeatedly filled in by teachers and investigation protocols performed by research team workers data for the Brno sample of children was collected on the occurrence of signs indicating more serious problems with school assignment fulfiling and behavior disorders in the childrens' 8,11 and 13 years of age. According to mothers' statements about their smoking behavior during pregnancy, the children were divided into two groups: prenatally exposed and non-exposed. The frequency differences of individual traits were evaluated in the SPSS statistical program (Pearson's $x^{2}$ test and linear associations, probability relations).

Results: In the ELSPAC study set the occurrence of inferior schoolwork performance evaluated based on term-report grades was more frequent in children prenatally exposed to mothers' smoking, along with more frequently diagnosed disorders which to significant extent implicate these inferior results and also special care needs occurred more frequently when compared to their peers born to non-smoking mothers. In the prenatally exposed subset also more frequent occurrence of various signs characterizing behavior disorders including attention disorders, hyperactivity, aggressiveness and signs of delinquency behavior were recorded.

Conclusions: The Czech ELSPAC cohort confirmed the results of other studies; within it was documented that children born to smoking mothers have more frequent behavioral problems and problems with fulfilling their school assignments in the school age period.
\end{abstract}

Key words: maternal smoking, pregnancy, behaviour problems, ELSPAC

Address for correspondence: L. Kukla, Research Institute of Preventive and Social Paediatrics, Faculty of Medicine, Masaryk University, Brno, Czech Republic. E-mail: lubomir.kukla@tiscali.cz

\section{INTRODUCTION}

A growing evidence of published results indicates that children and adolescents prenatally exposed to tobacco smoke may have higher rates of conduct disorders, including Attention Deficit Hyperactivity Disorder (ADHD), compared with un-exposed children (1-4). In some studies, the problems were more evident among boys than girls, especially in school age (5), but another study has found that females may be more sensitive than males (6). Although the methods of such studies are complicated by many confounding factors, as smokers have a tendency to differ on many socio-behavioral characteristics, the review of literature controlled for an array of potential confounders showed that prenatal exposure to cigarette smoke increased the risk of behavioral problems during childhood, adolescence and early adulthood $(7,8)$.

Although the relationship between exposure to tobacco smoke and offsprings' behavioral problems can be mediated both by other genetic predispositions and postnatal environmental conditions; some longitudinal prospective studies showed that the conduct disorders are moderately stable over time (8-10). These reasons have supported the recommendations of international examination of preventable risk factors (11).

Some investigators suggested that prenatal exposure to maternal smoking may also affect the cognitive development, leading to language ability, lower performance on arithmetic and spelling tasks (12), language performance (13), verbal learning (14) and consequent intellectual delays. 


\section{MATERIAL AND METHODS}

In the European Longitudinal Study of Pregnancy and Childhood (ELSPAC), both the markers of conduct disorders, learning problems and antenatal exposure to maternal smoking are collected. The Czech sample includes the cohort of children born at the beginning of 90' in the City Brno and rural district Znojmo (South Moravia). The analyzed data described in this paper were taken from the teachers' reports and medical observations of individual children born in Brno City in 1991/2, in their ages 8, 11 , and 13 years.

The prospective analysis of data obtained both from questionnaires repeatedly filled by parents, physicians, teachers and observations made by physicians and the research team. Prenatal exposure of children to cigarette smoke was assessed from the information about smoking behavior during pregnancy given by their mothers after delivery.

Teachers of children attending the 2nd class (age 8 years), 5th class (age 11 years) and 7th class (age 13 years) of primary schools filled a set of questionnaires; among others, data about some behavioral problems and markers of poor school performance were collected. The school performances were assessed on the scale from 1 (the best) to 5 (the worst). The occurrence of conduct disorders was expressed at 3-point scale as "never true", "sometimes true", "almost all the time true". The items included following: cheats or lies, breaks things, has trouble getting along with teachers and children, bullies other children, is sullen or irritable, has a very strong temper, difficulty concentrating, impulsivity, is overly active, cannot sit still. No teacher was informed about the history of exposure and/or results of physicians' observations. Additionally, some data focused at the similar topics were also obtained from the protocols of observation made independently by members of the research team. During the repeated observations different teachers, but the same staff members have participated on the study.

The analysis of relationships between prenatal exposure to smoking and behavioral - performance outcomes were prepared for two groups of children: those, whose mothers smoked dur-

Table 1. Numbers of children examined in particular developmental phases

\begin{tabular}{|l|c|c|c|c|}
\hline \multicolumn{2}{|c|}{} & \multicolumn{3}{|c|}{ Prenatal exposure } \\
\hline Numbers of examined children & Age-years & Yes & No & Sum \\
\hline Teachers & 8 & 169 & 1,291 & 1,460 \\
\hline & $\%$ & 11.6 & 88.4 & \\
\hline Teachers & 11 & 90 & 860 & 950 \\
\hline & $\%$ & 9.5 & 90.5 & \\
\hline Teachers & 13 & 82 & 799 & 881 \\
\hline & $\%$ & 9.3 & 90.7 & \\
\hline Investigation team & 8 & 43 & 432 & 475 \\
\hline & $\%$ & 9.1 & 90.9 & \\
\hline Investigation team & 11 & 59 & 540 & 599 \\
\hline & $\%$ & 9.8 & 90.2 & \\
\hline Investigation team & 13 & 30 & 405 & 435 \\
\hline & $\%$ & 6.9 & 93.1 & \\
\hline
\end{tabular}

ing the whole pregnancy and those, whose mothers have never smoked.

The socioeconomic status of mothers smoking and non-smoking during pregnancy from the Brno-City, measured by the type of flat (typical Czech town-flat with 2 or 3 rooms, central heating, warm and cold water), number of children living in family, an average length of parents' education (in years) was similar and differences were not significant. The controversial relationships between mothers and newborns after delivery were reported only rarely both by non-smoking and smoking women. Thus these confounding factors were not involved in the analysis studying relationships between prenatal cigarette smoke exposure and behavioral and learning problems during school age.

The statistic methods in SPSS programme (Pearson's $\chi^{2}$ test and linear associations, probability relations) were used for evaluation of significance of differences.

\section{RESULTS}

There were investigation results available for data analyses from various numbers of children in the particular time periods. After dividing the whole set into two groups according to mother's smoking data during pregnancy there was in all cases around $10 \%$ occurrence of prenatally exposed children (Table 1).

During the frequency analysis of below-average performing children (school grades 4 and 5) we observed worse school work performance both in the age of 8 and 11 years in classes requiring intelectual abilities (reading, arithmetic) and also in classes requiring manual and motoric abilities (writing, art classes) in children whose mothers smoked during pregnancy. In the next investigation phase at 13 years of age the differences between the exposed and non-exposed groups have been erased: in both groups the number of the children classified as below-average students has increased; more so in the non-exposed group (three and more times) than in the prenatally exposed group (most indices increased twice). Significant differences only persist in the 13-year-old students in their mathematical performance assessments which were more often weak in the prenatally exposed children. Also the original differences between both groups when evaluating motoric and manual capabilities have evened: while in exposed children the evaluation remained at the same level, their numbers in the nonexposed group have increased (Table 2 - Part A).

When information about average school work results (mark "3") was also available the differences between exposed and nonexposed groups of children were more pronounced and persisted in all investigation phases (Table 2 - Part B). The information collected from the research team protocols which among others followed the children' school work by the term reports (occurrence of grades 3,4 , eventually 5 ) also contributed to the above stated conclusions.

Other problems which can condition children working at school (dysgraphia, dysorthographia, dyslexia, dyspraxia, dyscalculia) which were also investigated by the research team, were in the younger age only reported summarily, at later phases also with particular disorder frequencies. Investigation in all age stages revealed these difficulties in more than one fifth of children whose mothers did not smoke. In the prenatally exposed group the frequency of objectively diagnosed disorders was higher, 
Table 2. Problems with school work

\begin{tabular}{|c|c|c|c|c|c|}
\hline \multirow[t]{3}{*}{ Attribute } & \multirow[t]{3}{*}{ Age } & \multicolumn{4}{|c|}{ Prenatal exposure } \\
\hline & & \multicolumn{2}{|c|}{ Part A } & \multicolumn{2}{|c|}{ Part B } \\
\hline & & Yes & No & Yes & No \\
\hline \multirow{3}{*}{ Reading } & 8 & 3.4 & 1.7 & $25.9^{\star \star \star}$ & 14.2 \\
\hline & 11 & $5.3^{\star}$ & 2.4 & $23.6^{\star \star}$ & 12.5 \\
\hline & 13 & 10.3 & 10.3 & 59.0 & 52.3 \\
\hline \multirow{3}{*}{$\begin{array}{l}\text { Writing, composition, } \\
\text { literature }\end{array}$} & 8 & $4.4^{*}$ & 3.5 & $25.7^{\star \star}$ & 20.8 \\
\hline & 11 & $6.7^{\star \star \star}$ & 1.7 & $31.4^{\star \star \star}$ & 17.8 \\
\hline & 13 & 13.1 & 9.3 & $73.6 !$ & 61.5 \\
\hline \multirow{3}{*}{ Algebra } & 8 & $4.7^{\star \star \star}$ & 1.1 & $14.6^{\star * \star}$ & 6.0 \\
\hline & 11 & $6.7^{\star \star \star}$ & 1.7 & $24.5^{\star \star \star}$ & 11.3 \\
\hline & 13 & $15.2^{*}$ & 8.4 & $76.0^{\star \star \star}$ & 52.9 \\
\hline \multirow{3}{*}{ General knowledge } & 8 & 3.0 & 1.5 & $28.9 * \star \star$ & 10.6 \\
\hline & 11 & 3.4 & 1.4 & $29.8^{\star \star \star}$ & 12.5 \\
\hline & 13 & 7.8 & 4.5 & $68.8^{*}$ & 51.6 \\
\hline \multirow{3}{*}{ Motoric abilities } & 8 & 2.9 & 2.4 & $15.8^{\star \star}$ & 9.6 \\
\hline & 11 & 2.2 & 1.7 & 16.8 & 13.0 \\
\hline & 13 & 5.2 & 6.1 & 48.1 & 48.2 \\
\hline \multirow{3}{*}{ Manual skills } & 8 & $3.6^{*}$ & 1.6 & $17.8^{\star}$ & 11.6 \\
\hline & 11 & 2.2 & 1.3 & $18.3^{\star \star}$ & 8.9 \\
\hline & 13 & 3.9 & 3.4 & 64.5 & 57.6 \\
\hline
\end{tabular}

(Part A - below average results - grades 4 and 5 according to teachers' evaluation - \% of occurrence, Part B - average and below average results - grades 3 and 4 and 5 according to teachers' evaluation - \% of occurrence)

Statistic significance: ${ }^{*}=p<0.05 ;{ }^{* \star}=p<0.01 ;{ }^{* \star *}=p<0.001 ; !=p<0.06$

and increased with age: in 13 years of age the disorders were observed in more than a third of the investigated set. The difference between both groups has occurred especially in dysgraphia and dysorthographia, the rest of the examined disorders occurred with similar frequencies. The mentioned and specialist diagnosed problems were in one quarter of non-exposed and in almost $42 \%$ of exposed children resolved by transfer into a special needs school or special needs class ( $\mathrm{p}<0.05)$; a quarter of both groups had a tutor to help with learning and most affected children (73\% of non-exposed and $84 \%$ exposed) were in a specialized clinical consulting care (Table 3).

Table 3. The investigation team examination outcomes (\% of children with problems)

\begin{tabular}{|c|c|c|c|}
\hline Attribute & Age & \multicolumn{2}{|c|}{ Prenatal exposure } \\
\hline & & Yes & No \\
\hline \multirow{3}{*}{ Results average-below average } & 8 & $9.3^{* \star *}$ & 1.4 \\
\hline & 11 & $6.8^{\star *}$ & 1.1 \\
\hline & 13 & $16.6^{* \star}$ & 8.9 \\
\hline \multirow{3}{*}{ Other school difficulties } & 8 & 23.3 & 22.1 \\
\hline & 11 & 22.0 & 20.0 \\
\hline & 13 & $36.7 !$ & 22.2 \\
\hline \multirow{3}{*}{$\begin{array}{l}\text { From that dysgraphia } \\
\text { dysortographia }\end{array}$} & 8 & $75.0^{*}$ & 48.3 \\
\hline & 11 & $52.9 !$ & 33.9 \\
\hline & 13 & 54.5 ! & 44.4 \\
\hline
\end{tabular}

Statistic significance: ${ }^{*}=p<0.05 ;{ }^{* \star}=p<0.01 ;{ }^{* \star}=p<0.001 ; !=p<0.06$
The indexes used to evaluate child school behavior were common, repeatedly used in various investigation phases as well as specifically formulated for each age category. In the field of repeatedly used indexes both child groups differed on a long-term basis in the attention/focus disorder frequency and in motoric hyperactivity manifestation frequency which were significantly more often observed in prenatally exposed children (Table 4). Other manifestations of disturbed behavior (mood instability, aggressiveness, purposeful lying) occurred in the teachers' sheets on 8-year-old and 11-year-old children, with significantly higher frequency in prenatally exposed while in the 13-year-old population the frequency decreased and was similar in both investigated groups. Among the exposed children in their younger age the teachers' information on children stealing something in the school was recorded more often, in the 13-year-olds happened only two cases of such wrongdoing.

Table 4. Selected behavior disorders occurring occasionally to often according to teachers' reports (\% of children with problems)

\begin{tabular}{|c|c|c|c|}
\hline \multirow[t]{2}{*}{ Attribute } & \multirow[t]{2}{*}{ Age } & \multicolumn{2}{|c|}{ Prenatal exposure } \\
\hline & & Yes & No \\
\hline \multirow{3}{*}{$\begin{array}{l}\text { Lack of attention, } \\
\text { concentration }\end{array}$} & 8 & $68.4^{\star \star \star}$ & 53.2 \\
\hline & 11 & $44.5^{\star \star}$ & 27.9 \\
\hline & 13 & $45.7^{\star \star \star}$ & 25.3 \\
\hline \multirow{3}{*}{ Writhes about constantly } & 8 & $53.5^{\star \star \star}$ & 38.5 \\
\hline & 11 & $36.7^{\star \star \star}$ & 22.1 \\
\hline & 13 & $24.6^{\star \star}$ & 15.9 \\
\hline \multirow{3}{*}{$\begin{array}{l}\text { Mood sways, } \\
\text { anger outbursts }\end{array}$} & 8 & $36.8^{\star \star}$ & 24.6 \\
\hline & 11 & $14.8^{\star \star}$ & 7.7 \\
\hline & 13 & 8.8 & 5.5 \\
\hline \multirow{3}{*}{ Provokes fights } & 8 & $37.7^{\star \star}$ & 26.8 \\
\hline & 11 & $28.7^{\star \star \star}$ & 11.3 \\
\hline & 13 & 2.5 & 1.1 \\
\hline \multirow{3}{*}{ Hurts other children } & 8 & $24.2^{\star}$ & 17.2 \\
\hline & 11 & 5.6 & 5.6 \\
\hline & 13 & 2.5 & 1.1 \\
\hline \multirow{3}{*}{ Lies to avoid duty } & 8 & $37.7^{\star \star \star}$ & 19.1 \\
\hline & 11 & $12.8^{\star \star}$ & 5.7 \\
\hline & 13 & 3.8 & 2.6 \\
\hline \multirow{3}{*}{ Tooks/stoles something } & 8 & $11.6^{\star \star \star}$ & 3.6 \\
\hline & 11 & $21.2^{\star \star \star}$ & 8.5 \\
\hline & 13 & \multicolumn{2}{|c|}{ only individual attempts } \\
\hline
\end{tabular}

Statistic significance: ${ }^{*}=p<0.05 ;{ }^{* \star}=p<0.01 ;{ }^{* \star}=p<0.001$

The significant differences in hyperactivity manifestation between both groups of children examined at 8 years of age are confirmed by the data stated in Table 5 including the significantly more frequent necessity of special pedagogical-social care in children born to smoking mothers.

In a section of a questionnaire for older-school-age children dedicated especially to particular behavior disorders aspects, in the majority of indexes the higher frequences occur in children with prenatal exposure; statistically significant are the differences in attention deficit/focus disorder and breaking school behavior 
Table 5. Selected behavior disorders at the age of 8 years (reported by teacher as "often" and "almost all the time") $\%$ of children with problems

\begin{tabular}{|l|c|c|}
\hline & \multicolumn{2}{|c|}{ Prenatal exposure } \\
\hline Attribute & Yes & No \\
\hline Child is hyperactive & $22.4^{\star \star}$ & 13.2 \\
\hline Child's behavior disrupts class & $13.5^{\star}$ & 8.1 \\
\hline $\begin{array}{l}\text { Child performs inappropriate } \\
\text { spontaneous movements }\end{array}$ & $27.7^{\star * \star}$ & 16.0 \\
\hline Child needs special pedagogical care & $27.7^{\star \star *}$ & 16.4 \\
\hline
\end{tabular}

Statistic significance: ${ }^{*}=p<0.05 ;{ }^{* *}=p<0.01 ;{ }^{* *}=p<0.001$

norms for which various discipline measures were taken. Problem is that children more often find friends who also break social behavior norms. At the investigation in 11 years of age the teachers observed in the exposed children a more frequent occurrence of learning problems related to lack of subject understanding, during the second investigation the frequence of this information was similar in both groups (Table 6). The lack of attention, easy distractibility and hyperactive behavior which often disturbs the work of the whole class were all significantly more often present in prenatally exposed children not only in the long-term horizon

Table 6. Selected behavior disorders at the age of 11 and 13 years (reported by teacher) - \% of children with problems

\begin{tabular}{|c|c|c|c|}
\hline \multirow[b]{2}{*}{ Attribute } & \multicolumn{3}{|c|}{ Prenatal exposure } \\
\hline & Age & Yes & No \\
\hline \multirow{2}{*}{$\begin{array}{l}\text { Behavior problems } \\
\text { (frequent warnings, offenses, lowered grade) }\end{array}$} & 11 & $30.3^{\star * *}$ & 14.8 \\
\hline & 13 & $31.7^{\star \star \star}$ & 16.0 \\
\hline \multirow{2}{*}{$\begin{array}{l}\text { Emotional instability } \\
\text { (tearfulness, disheartedment) }\end{array}$} & 11 & $23.6 !$ & 16.1 \\
\hline & 13 & 9.8 & 11.9 \\
\hline \multirow{2}{*}{$\begin{array}{l}\text { Attention problems } \\
\text { (lack of concentration, restlessness) }\end{array}$} & 11 & $43.8^{*}$ & 31.2 \\
\hline & 13 & $50.0^{\star \star \star}$ & 29.8 \\
\hline \multirow{2}{*}{$\begin{array}{l}\text { Memory problems } \\
\text { (inadequate endowment, inability to remember) }\end{array}$} & 11 & $37.8^{\star \star \star}$ & 21.9 \\
\hline & 13 & 21.0 & 16.8 \\
\hline \multirow{2}{*}{$\begin{array}{l}\text { Learning disabilities } \\
\text { (problems understanding the subject matter) }\end{array}$} & 11 & $37.8^{\star \star \star}$ & 19.6 \\
\hline & 13 & 25.9 & 21.6 \\
\hline \multirow{2}{*}{ Problems with social contacts } & 11 & $20.0 !$ & 12.9 \\
\hline & 13 & 8.6 & 10.0 \\
\hline \multirow{2}{*}{ Chooses friends who break the norms } & 11 & $30.2^{\star \star \star}$ & 12.3 \\
\hline & 13 & $14.1^{*}$ & 7.1 \\
\hline \multirow{2}{*}{ Stubborn negativism } & 11 & $6.4^{*}$ & 2.3 \\
\hline & 13 & 7.5 & 5.9 \\
\hline \multirow{2}{*}{ Excessive fastidiousness } & 11 & 9.9 & 9.8 \\
\hline & 13 & $9.5^{\star \star}$ & 1.3 \\
\hline \multirow{2}{*}{ Aggressiveness } & 11 & $11.9 !$ & 6.5 \\
\hline & 13 & 6.3 & 5.1 \\
\hline \multirow{2}{*}{ Inadequate reactions } & 11 & 16.7 & 11.3 \\
\hline & 13 & 17.5 & 12.7 \\
\hline
\end{tabular}

Statistic significance: ${ }^{*}=p<0.05 ;{ }^{* *}=p<0.01 ;{ }^{* \star}=p<0.001 ; !=p<0.06$ point of view but also in teacher's evaluation of the child during the last 6 months ( $35.5 \%$ vs $17.3 \%, \mathrm{p}<0.001)$.

When assessing the class social interactions, most 11-year-old and 13-year-old childrens' position was evaluated by their teacher as positive: the others accept and appreciated them (cса 80\%) eventually tolerated them (cca 10\%): for about $10 \%$ of children the choice "is connived" was selected and only in solitary cases $(<1 \%)$ the children are rejected by their peers and even can be classified as "victims". There were however no differences between groups in this aspect.

The children with different prenatal exposure also have a different family social background; five times more often did the teachers inform about inadequate parents' interest for their childrens' school life in the 5th-9th grade within the prenatally exposed group (2.2-2.5\% non-exposed and 10.9-12.8\% exposed).

\section{DISCUSSION}

The link between in utero exposure to tobacco smoke and conduct disorders/attention deficit, hyperactivity disorder has been described through meta-analyses of studies published over a 30-year period (2), twin studies (3), and studies controlling socioeconomic status and post-natal complications (12).

While the conduct disorders in childhood were usually strongly associated with the retardant prenatal somatic development, the altered brain functions can be present even in the absence of low birth weight $(15,16)$. Children prenataly exposed to mother's smoking had lower score in standardized tests of language development at 3 and 4 years of age (17). Reviewed 17 studies described more strong associations of health a cognitive problems in children exposed to passive smoking both during prenatal and postnatal period than of those exposed only prenatally (18). It is important that significant relationship remains stable after controlling for a wide range of confounding factors (19). On the other hand, in some studies no significant differences in speech and language abilities between exposed and non-exposed children were described (20).

The mechanisms of prenatal smoke exposure effects on cognitive development are not well understood yet: both the structural and functional development within specific regions on the brain related to the behavioral and cognitive problems can be affected $(7,12)$. The possible biological mechanisms include chronic hypoxemia, alteration in the cholinergic, noradrenergic and dopaminergic neurotransmitter systems, influence on cell differentiation and their damage in cerebral and cerebellar cortex, as well as in basal ganglia (15).

Detrimental effect of prenatal exposure to cigarette smoking on the brain development is suggested by the indirect evidence of significant negative correlation to the head circumference at birth (21, 22), which were found also in the Czech ELSPAC cohort, despite of the similar lenghts of the pregnancy both among the non-exposed and exposed groups (23). The subnormal head circumference is associated with the well-known neurobehavioral consequences: damages of cognitive function and neuropsychological abilities at school age (24), ADHD (25) and schizophrenia (26).

The lowered thickness of the different parts of cerebral cortex (orofrontal, middle frontal, parahippocampal) measured using the magnetic resonance were described among adolescents exposed 
prenatally to maternal smoking. The effects were significant mainly in female adolescents and were related to several markers of cognition and social behavior (6). The more detailed damages of brain structure caused by the exposure to cigarette smoke were shown in experimental studies: reduction of brain weight, cortical thickness in different regions (27), cytoplasmatic vacuolation, intracellular spaces enlargement, increased number of apoptosis cells (28). Also volumetric measurements of children born preterm (at their age of 8 years) showed smaller volumes of the sensori-motor cortex and other cortical areas, as well as in the corpus callosum, amygdala, hippocampus and basal ganglia: these objective changes were associated with lower cognitive scores and increased prevalence of behavioral problems, including ADHD (29). The similar results were found using the magnetic resonance methods for 14-year-old preterm born children (30).

A meta-analysis of 15 studies offering the cognitive data and another of 16 studies with behavioral data described a strong relationship of lower cognitive scores and increasing evidence of externalizing and internalizing behaviors to preterm-born children in their school age (31). The mean cognitive test scores were strongly correlated with the birth weight and gestation at birth and there were no significant differences between results obtained from different countries. The mean differences between the cognitive scores of school-aged classes and controls reached the value 10.9 points, which may have an important impact on the educational requirements. Authors believe that prenatal and perinatal circumstances caused preterm delivery and/or antenatal growth retardation can influence brain cells development and maturation with consequent volumetric losses in specific brain regions and may partially explain the cognitive and behavioral abnormalities. It is widely accepted that prenatal exposure to smoking is the main risk factor for increased incidence of aborts, preterm birth and fetal growth retardation.

According to contemporal knowledge, prenatal exposure to tobacco smoke may change also the functional brain development through the effect on a number of neurotransmitter systems (dopamine, serotonine, acetylcholine) which can persist and modify maturation changes during childhood and adolescence (32).

In the ELSPAC study set of children prenatally exposed to their mothers' smoking more frequent inferior school work results (according to term-reports), more frequent disorder diagnoses which to a higher extent implicate the worse results and also more frequent special care needs were found compared to children born to non-smoking mothers. In the prenatally exposed children set there was also repeatedly found a more frequent occurrence of various traits which characterize behavioral disorders including attention disorders, hyperactivity, aggressiveness and delinquency behavior signs. In this aspect the Czech ELSPAC study cohort has confirmed the results of other foreign studies.

The associations of antenatal exposure to tobacco smoke and changes in psycho-motoric development were found in the ELSPAC cohort also during the pre-school childhood. The prenatal exposure to maternal smoking was significantly related to more frequent absence of skills requiring more complicated motoric coordination, as well as to the occurrence of absentmindedness, poorer concentration, hyperactivity, absence of social plays and contacts with other children, and manifestation of aggressive behavior at the age of 3 years, and more frequent signals of possible delay in school maturity development at the age of 5 years (33).

It was not able completely rule out a certain social conditions influence which in some aspects differed in both compared groups; the mothers who smoked during the whole pregnancy were more often less educated and according to teachers' data they expressed lower interest in their childrens' school work. At the start of their life, children of smoking mothers were less breast fed: at the end of confinement ( 6 weeks after delivery) only $25 \%$ of children of smoking mothers were breast fed exclusively, compared to $54 \%$ of children born to non-smoking women (34). The analysis of ELSPAC data about mothers' relationships to their children after birth and during the confirment found a lower contact of smoking mother and child in lying-in hospital; more women in the smoking group indicated that they had not developed a full emotional relationship with the child during the whole confinement and that they usually reacted to the child's needs expressed by its crying with delays. The maternal lower socio-economic status influenced this way of behavior to a greater extent. The mother-child unit was also more often disrupted as children of smoking mothers were more frequently hospitalized during the confinement (35). Nevertheless, these poorer psycho-social conditions after birth occurred only rarely, in about $2-9 \%$ of exposed and $1-6 \%$ of non-exposed, and thus they could contribute only partially to the school-related problems.

\section{CONCLUSIONS}

Child behavior and school performance is influenced by many genetic and environmental factors including prenatal exposure to chemical neurotoxins contained in cigarette smoke. The Czech ELSPAC cohort confirmed the results of other studies; within it was documented that children born to smoking mothers have more frequent behavioral problems and problems with fulfilling their school assignments in the school age period. These results are another strong reason for the further wide anti-smoking activities. In the Czech Republic, the widely used educational school-based anti-smoking programme „Smoking and Me“ involves lectures concerning the risks of smoking during pregnancy for the fetus and child (at the part for 13 years old students). Another interventional anti-smoking programme has been created for pregnant women and the methods of interventions for "healthy lifestyle during pregnancy“ and forms an important part of the curriculum for university students - future health professionals.

\section{Acknowledgments}

This work was supported by grant IGA MH CR no. NR 8791-2.

\section{REFERENCES}

1. DiFranza JR, Aligne CA, Weitzman M. Prenatal and postnatal environmental tobacco smoke exposure and children's health. Pediatrics. 2004 Apr;113(4 Suppl):1007-15.

2. Linnet KM, Dalsgaard S, Obel C, Wisborg K, Henriksen TB, Rodriguez A, et al. Maternal lifestyle factors in pregnancy risk of attention deficit hyperactivity disorder and associated behaviors: review of the current evidence. Am J Psychiatry. 2003 Jun;160(6):1028-40. 
3. Thapar A, Fowler T, Rice F, Scourfield J, van den Bree M, Thomas $\mathrm{H}$, et al. Maternal smoking during pregnancy and attention deficit hyperactivity disorder symptoms in offspring. Am J Psychiatry. 2003 Nov;160(11):1985-9.

4. Weitzman M, Gortmaker S, Sobol A. Maternal smoking and behavior problems of children. Pediatrics. 1992 Sep;90(3):342-9.

5. Wakschlag LS, Hans SL. Maternal smoking during pregnancy and conduct problems in high-risk youth: a developmental framework. Dev Psychopathol. 2002;14(2):351-69.

6. Toro R, Leonard G, Lerner JV, Lerner RM, Perron M, Pike GB, et al. Prenatal exposure to maternal cigarette smoking and the adolescent cerebral cortex. Neuropsychopharmacology. 2007 Jul 4;doi:10.1038/ sj.npp.1301484.

7. Olds D. Tobacco exposure and impaired development: a review of the evidence. Ment Retard Dev Disabil Res Rev. 1997;3(3):257-69.

8. Sourander A, Multimäki P, Nikolakaros G, Haavisto A, Ristkari T, Helenius $\mathrm{H}$, et al. Childhood predictors of psychiatric disorders among boys; a prospective community-based follow-up study from age 8 years to early adulthood. J Am Acad Child Adolesc Psychiatry. 2005 Aug;44(8):75667.

9. Campbell SB. Behavior problems in preschool children: a review of recent research. J Child Psychol Psychiatry. 1995 Jan;36(1):113-49.

10. Gray RF, Indurkhya A, McCormick MC. Prevalence, stability, and predictors of clinically significant behavior problems in low birth weight children at 3, 5, and 8 years of age. Pediatrics. 2004 Sep;114(3):73643.

11. Carter S, Paterson J, Gao W, Iusitini L. Maternal smoking during pregnancy and behaviour problems in a birth cohort of 2-year-old Pacific children in New Zealand. Early Hum Dev. 2008 Jan;84(1):59-66.

12. Batstra L, Hadders-Algra M, Neeleman J. Effect of antenatal exposure to maternal smoking on behavioural problems and academic achievement in childhood: prospective evidence from a Dutch birth cohort. Early Hum Dev. 2003 Dec;75(1-2):21-33.

13. Fried PA, Watkinson B, Siegel LS. Reading and language in 9- to 12-year olds prenatally exposed to cigarettes and marijuana. Neurotoxicol Teratol. 1997 May-Jun;19(3):171-83.

14. Cornelius MD, Ryan CM, Day NL, Goldschmidt L, Willford JA. Prenatal tobacco effects on neuropsychological outcomes among preadolescents. J Dev Behav Pediatr. 2001 Aug;22(4):217-25.

15. Ernst M, Moolchan ET, Robinson ML. Behavioral and neural consequences of prenatal exposure to nicotine. J Am Acad Child Adolesc Psychiatry. 2001 Jun;40(6):630-41.

16. Key AP, Ferguson M, Molfese DL, Peach K, Lehman C, Molfese VJ. Smoking during pregnancy affects speech-processing ability in newborn infants. Environ Health Perpect. 2007 Apr;115(4):623-9.

17. Fergusson DM, Horwood LJ, Lynskey MT. Maternal smoking before and after pregnancy effects on behavioral outcomes in middle childhood. Pediatrics. 1993 Dec;92(6):815-22.

18. Eskenazi B, Castorina R. Association of prenatal maternal or postnatal child environmental tobacco smoke exposure and neurodevelopmental and behavioral problems in children. Environ Health Perspect. 1999 Dec;107(12):991-1000.

19. Olds DL, Henderson CR Jr, Tatelbaum R. Intellectual impairment in children of women who smoke cigarettes during pregnancy. Pediatrics. 1994 Feb;93(2):221-7. Erratum in: Pediatrics 1994 Jun;93(6 Pt 1):973.
20. Makin J, Fried PA, Watkinson B. A comparison of active and passive smoking during pregnancy: long-term effects. Neurotoxicol Teratol. 1991 Jan-Feb;13(1):5-12.

21. Källén K. Maternal smoking during pregnancy and infant head circumference at birth. Early Hum Dev. 2000 Jun;58(3):197-204.

22. Roza SJ, Verburg BO, Jaddoe VW, Hofman A, Mackenbach JP, Steegers EA, et al. Effects of maternal smoking in pregnancy on prenatal brain development. The Generation R Study. Eur J Neurosci. 2007 Feb;25(3):611-7.

23. Kukla L, Hrubá D, Tyrlík M; European Longitudinal Study of the Pregnancy and childhood. Smoking and damages of reproduction. Cent Eur J Public Health. 2001May;9(2):59-63.

24. Peterson J, Taylor HG, Minich N, Klein N, Hack M. Subnormal head circumference in very low birth weight children: neonatal correlates and school-age consequences. Early Hum Dev. 2006 May;82(5):325-34.

25. Castellanos FX, Giedd JN, Marsh WL, Hamburger SD, Vaituzis AC, Dickstein DP, et al. Quntitative brain magnetic resonance imaging in attention-deficit hyperactivity disorder. Arch Gen Psychiatry. 1996 Jul;53(7):607-16.

26. Eliez S, Reiss AL. MRI neuroimaging of childhood psychiatric disorders: a selective review. J Child Psychol Psychiatry. 2000 Sep;41(6):679-94.

27. Roy TS, Andrews JE, Seidler FJ, Slotkin TA. Nicotine evokes cell death in embryonic rat brain during neurulation. J Pharmacol Exp Ther. 1998 Dec;287(3):1136-44.

28. Levitt P. Prenatal effects of drugs of abuse on brain development. Drug Alcohol Depend. 1998 Jun-Jul;51(1-2):109-25.

29. Peterson BS, Vohr B, Staib LH, Cannistraci CJ, Dolberg A, Schneider $\mathrm{KC}$, et al. Regional brain volume abnormalities and long-term cognitive outcome in preterm infants. JAMA. 2000 Oct 18;284(15):1939-47.

30. Stewart AL, Rifkin L, Amess PN, Kirkbride V, Townsend JP, Miller $\mathrm{DH}$, et al. Brain structure and neurocognitive and behavioural function in adolescents who were born very preterm. Lancet. 1999 May 15;353(9165):1653-7.

31. Bhutta AT, Cleves MA, Casey PH, Cradock MM, Anand KJ. Cognitive and behavioral outcomes of school-aged children who were born preterm: a meta-analysis. JAMA. 2002 Aug 14;288(6):728-37.

32. Slotkin TA, Tate CA, Cousins MM, Seidler FJ. Prenatal nicotine exposure alters the responses to subsequent nicotine administration and withdrawal in adolescence: serotonin receptors and cell signaling. Neuropsychopharmacology. 2006 Nov;31(11):2462-75

33. Kukla L, Hrubá D, Tyrlík M. Smoking of mothers during pregnancy in relation to mental and motoric development disorders in 3- and 5- yearold children. The ELSPAC study results. Psychol Patopsychol Diet'at'a. 2006;41(1):39-49. (In Czech.)

34. Kukla L, Hrubá D, Tyrlík M. Influence of mothers's smoking on nutrition of children during firts six weeks after birth. The ELSPAC study results. Českoslov Pediatr. 2004;59(1):31-7. (In Czech.)

35. Kukla L, Hrubá D, Tyrlík M. Relationships of smoking and nonsmoking mothers with their newborn children. Psychol Patopsychol Diet'at'a. 2003;38(4):291-301. (In Czech.) 